\title{
Two SNPs Associated with Type 2 Diabetes and Obesity at Melanocortin-4 Receptor Gene Loci Exhibited High Fst Values and Natural Selection
}

\section{Issei Yoshiuchi*}

Departments of Genetics, Diabetes Mellitus, and Medicine, Yoshiuchi Medical Diabetes Institute, Japan

\begin{abstract}
Background: Human adaptation to environmental changes in food supply, lifestyle, and geography may have initiated the selection of genes associated with the metabolism of glucose, lipids, carbohydrates, and energy. Obesity is significantly associated with type 2 diabetes mellitus, metabolic syndrome, hypertension, stroke, and cardiovascular diseases. The worldwide prevalence of obesity and type 2 diabetes is increasing steadily. Obesity and type 2 diabetes are highly heritable diseases that cause serious health problems. The melanocortin- 4 receptor gene is one of the major obesity genes, and common genetic variations near the melanocortin- 4 receptor gene were found to be associated with obesity, type 2 diabetes, and insulin resistance. We aimed to uncover evidence of selection at melanocortin-4 receptor gene loci using single-nucleotide polymorphisms (SNPs) associated with type 2 diabetes and obesity.
\end{abstract}

Methods: We analyzed melanocortin-4 receptor gene loci in HapMap populations to detect selection using a 3-step test: Wright's F-statistics (Fst) as a measure of population differentiation, the long-range haplotype (LRH) test to obtain evidence of positive selection by testing haplotypes, and integrated haplotype score (iHS).

Results: We observed one body mass index (BMI)-associated SNP (rs7227255) and one type 2 diabetesassociated SNP (rs11873305) that exhibited high Fst values, and showed high population differentiation and natural selection at the melanocortin-4 receptor gene loci.

Conclusion: This is the first report that SNPs associated with type 2 diabetes and obesity exhibited high Fst values in one-gene loci. Most of the SNPs associated with type 2 diabetes and obesity that were reported did not demonstrate high Fst values. Our findings are important for clinical medicine. We suggest that melanocortin-4 receptor agonists may be useful drugs for the treatment of obesity and type 2 diabetes, and that further studies should examine the adaptive evolution of obesity, type 2 diabetes, and insulin resistance genes.

Keywords: Natural selection ; MC4R; Obesity; Type 2 diabetes

\section{Introduction}

Obesity is one of the more significant diseases that comprise metabolic syndrome, and is a serious problem that results in morbidity and mortality worldwide. Obesity and type 2 diabetes were reported to be highly heritable diseases and genetic contribution to obesity is approximately $40-70 \%[1,2]$. Obesity is associated with many diseases, including type 2 diabetes, hypertension, stroke, cardiovascular diseases, and several cancers. The worldwide prevalence of obesity is increasing by the day and has more than doubled since 1980. According to the 2008 World Health Organization (WHO) Report, 1.5 billion adults were overweight, and of these, over 200 million men and nearly 300 million women were obese. Furthermore, $33.8 \%$ of the population in the US in 2007-2008 was obese [3].

The past 10,000 years, also known as the Holocene epoch, have witnessed significant developments in plant and animal domestication [4]. At the end of the last Ice Age approximately 10,000 years ago, humans underwent a significant lifestyle change from being hunters and gatherers to being farmers [4]. Natural selection allows adaptations to changes in human lifestyle and geography. Throughout the past 10,000 years, human genes associated with many important diseases, including those affiliated with infection $[5,6]$ and diabetes $[7,8]$, may have experienced adaptive evolution. Human adaptations to environmental changes in food supply, lifestyle, and geography may have pressured the selection of genes associated with the metabolism of glucose $[7,8]$, lipids and energy.
The melanocortin-4 receptor is associated with energy expenditure, food intake, and obesity [9], and is primarily expressed in the brain [10], but not expressed in the adrenal cortex and melanocytes [10]. Common variations near the melanocortin- 4 receptor $(M C 4 R)$ gene were found to be associated with obesity, type 2 diabetes, and insulin resistance [11-15]. Mutations of the MC4R gene were found to be associated with severe obesity, hyperphagia, and severe hyperinsulinemia [16].

In this study, we analyzed the MC4R gene loci to detect selection in HapMap populations [17] using a 3-step test that included Wright's F-statistics (Fst) as a measure of population differentiation $[18,19]$, the long-range haplotype (LRH) test to obtain evidence of positive selection by testing haplotypes [6], and the integrated haplotype score (iHS), which is a statistic based on the differential levels of linkage disequilibrium (LD) surrounding a positively selected allele compared with the background allele [20].

*Corresponding author: Issei Yoshiuchi, Departments of Genetics, Diabetes Mellitus, and Medicine, Yoshiuchi Medical Diabetes Institute, 2-16-41 Kamakurayama, Kamakura City, Kanagawa 248-0031, Japan, Tel: +81-467-31-8869; Fax: +81-46731-8869; E-mail: yoshiuchi@m9.dion.ne.jp

Received July 01, 2013; Accepted August 21, 2013; Published August 24, 2013

Citation: Yoshiuchi I (2013) Two SNPs Associated with Type 2 Diabetes and Obesity at Melanocortin-4 Receptor Gene Loci Exhibited High Fst Values and Natural Selection. J Diabetes Metab S11: 005. doi:10.4172/2155-6156.S11-005

Copyright: (c) 2013 Yoshiuchi I. This is an open-access article distributed under the terms of the Creative Commons Attribution License, which permits unrestricted use, distribution, and reproduction in any medium, provided the original author and source are credited. 
Citation: Yoshiuchi I (2013) Two SNPs Associated with Type 2 Diabetes and Obesity at Melanocortin-4 Receptor Gene Loci Exhibited High Fst Values and Natural Selection. J Diabetes Metab S11: 005. doi:10.4172/2155-6156.S11-005

We observed one body mass index (BMI)-associated singlenucleotide polymorphism (SNP) (rs7227255) and one type 2 diabetes mellitus-associated SNP (rs11873305) that exhibited high Fst values and demonstrated high population differentiation and natural selection at the MC4R gene loci. This is the first report that these type 2 diabetesand obesity-associated variants exhibited high Wright's F-statistics (Fst) values and showed natural selection in one-gene loci. Most of the SNPs that were associated with type 2 diabetes and obesity were reported not to demonstrate high Fst values.

\section{Subjects and Methods}

\section{Study populations}

For Wright's Fst analyses $[18,19]$, we used genotype data from 4 human HapMap populations, including Utah residents with Northern and Western European ancestry (CEU), Yoruba in Ibadan, Nigeria (YRI), Han Chinese in Beijing (CHB), and Japanese in Tokyo (JPT), from release 28 of HapMap data [17] (Supplementary Table 1).

For the LRH test [6], we used phased haplotype data of $60 \mathrm{CEU}$, 60 YRI, and 90 East Asian (including those from the CHB and JPT groups) individuals from release 24 of HapMap data [17].

For the iHS test [20], we used 3 HapMap populations from release 21 of the HapMap dataset [17], including CEU, YRI, and East Asian individuals.

\section{Statistical evaluation}

We examined a 3-step test, Wright's Fst $[18,19]$, the LRH test [6], and the iHS test [20] to detect selection in the MC4R loci using HapMap populations [17].

Wright's fixation index, Fst $[18,19]$, a measure of population differentiation, was calculated for the 4 HapMap populations with Arlequin integrated software (version 3.1; http://cmpg.unibe.ch/ software/arlequin3/) [21]. We tested four BMI-associated SNPs (rs6567160, rs571312, rs17782313, and rs7227255 [11,13,14]), one type 2 diabetes, waist circumference, and insulin resistance-associated SNP (rs12970134 [12]), and one type 2 diabetes-associated SNP (rs11873305 [15]), from MC4R loci (Supplementary Table 1). In previous studies that utilized Fst analysis, the global Fst for the 95th percentile of over 2,911,292 markers was 0.365 [22] in 4 HapMap populations, including that of CEU, YRI, CHB, and JPT populations [17], and the average Fst value was $\sim 0.15$ [23-26]. We compared the 6 Fst values with the 95th percentile of the Fst distribution (>0.365) [22].

The LRH test [6], which was performed to obtain evidence of positive selection by testing haplotypes, was performed with SWEEP (version 1.1: http://www.broadinstitute.org/mpg/sweep/index.html) [6]. Using the LRH test, specifically, the relative extended haplotype homozygosity (REHH) method [6], we scanned not only the 6 associated SNP regions but also the MC4R loci (Chr. 18, locations $55,980,000-56,500,000)$, and analyzed these loci with the complete chromosome 18 in each population.

The iHS, a statistic based on the differential levels of LD surrounding a positively selected allele as compared to the background allele, was calculated using the Haplotter web tool (http://haplotter.uchicago. edu/), which was accessed in January 2010 [20]. In the iHS test, an extreme positive score (iHS > 2.5) and an extreme negative score (iHS $<-2.5$ ) represent the highest $1 \%$ of the distribution of scores for all SNPs [20]. Furthermore, extreme positive scores ([iHS] 2.5) indicate recent positive selection at a locus [20]. The iHS has moderate power to detect a selection at intermediate frequency $(50-80 \%)$, but low power to detect a selection at high frequency $(>80 \%)$ or low frequency $(<30 \%)$ [27]. we tested the SNPs of the MC4R loci (Chr. 18, locus 55,980,000$56,500,000)$, and all iHS values were standardized [20].

\section{Results}

\section{Fst analysis}

We tested four BMI-associated SNPs $[11,13,14]$, one type 2 diabetes, waist circumference, and insulin resistance-associated SNP [12], and one type 2 diabetes-associated SNP [15], from the MC4R loci with Fst analysis (Table 1, Supplementary Table 1). We compared the 6 Fst values with the upper 95\% quantile of the distribution $(>0.365)$ [22] and found the highest Fst values in one BMI-associated SNP (rs7227255:0.42) and one type 2 diabetes-associated SNP (rs11873305:0.41) (Table 1). The two SNPs (rs7227255 and rs11873305) with the highest Fst values were located in a region approximately $9-16 \mathrm{~kb}$ upstream of $M C 4 R$. The other four SNPs with low Fst values were located in a region approximately 150-210 kb downstream of $M C 4 R$. In particular, the rs7227255 C risk allele of the MC4R loci is reportedly associated with BMI. Accordingly, the rs $7227255 \mathrm{C}$ risk allele may be thrifty genotype [28]. These findings are very interesting and the first report that both variants associated with type 2 diabetes and obesity exhibited high Fst values and showed natural selection in one-gene loci. Most of the associated SNPs were reported not to demonstrate high Fst values [22,27], but these results specifically presented associated SNPs themselves showed high Fst values.

\section{LRH test}

We found selection in the regions approximately 192-196 kb upstream, approximately $29-80 \mathrm{~kb}$ downstream, and approximately 134-145 kb downstream of MC4R in the CEU population (REHH percentile: 99.9) (Table 2). The gene nearest to these regions is $M C 4 R$, and these regions may be regulatory regions of MC4R. It has been reported that regions that are several hundred kilobases away from a gene could be regulatory regions [29]. These regions could be the actual target of selection in $M C 4 R$ loci.

\begin{tabular}{|c|c|c|c|c|c|c|}
\hline Gene & Associated SNP & Chr & Position & Risk/non risk & Associated phenotypes \\
\hline MC4R & rs6567160 & 18 & $55,980,105$ & G/A & BMI \\
\hline & rs571312 & & $55,990,739$ & A/C & BMI \\
\hline & rs17782313 & & $56,002,067$ & C/T & BMI \\
\hline & & & & & $\begin{array}{c}\text { Type 2 diabetes/ } \\
\text { Insulin resistance/ } \\
\text { Waist Circumference }\end{array}$ \\
\hline & rs12970134 & & $56,035,730$ & A/G & 0.05 \\
\hline & rs11873305 & & $56,200,172$ & A/C & Type 2 diabetes \\
\hline
\end{tabular}

*The reported $95 \%$ quantile of over 2,911,292 markers is 0.365 [22]. 
Citation: Yoshiuchi I (2013) Two SNPs Associated with Type 2 Diabetes and Obesity at Melanocortin-4 Receptor Gene Loci Exhibited High Fst Values and Natural Selection. J Diabetes Metab S11: 005. doi:10.4172/2155-6156.S11-005

Page 3 of 4

\begin{tabular}{|c|c|c|c|c|c|c|c|}
\hline Population & Associated SNP & Start Base & Length & Haplotype & REHH & REHH & REHH \\
\hline & & & & frequency & & percentile & P-value \\
\hline \multirow[t]{3}{*}{ CEU } & & 56045103 & 9888 & 0.308 & 8 & 99.9th & 0.012 \\
\hline & & 56109995 & 50411 & 0.308 & 9 & 99.9th & 0.010 \\
\hline & & 56383434 & 3202 & 0.167 & 31 & 99.9th & 0.007 \\
\hline YRI & rs65670 G risk and rs571312 C non-risk alleles & 55964628 & 26121 & 0.125 & 56 & 99.9th & 0.013 \\
\hline
\end{tabular}

ASN: East Asian including CHB and JPT

Table 2: The LRH test at the MC4R loci ( REHH percentile $\geq 99.9$ th ).

\begin{tabular}{|l|l|}
\hline Population & Number of SNPs with [iHS] $\mathbf{~ 2 . 5}$ (Total number of SNPs) Max [iHS] (rs number: Position) \\
\hline CEU & $0(514) 2.19$ (rs11660003:56374946) \\
\hline YR & $5(625) 2.89$ (rs12326252:56483425) \\
\hline ASN & $6(470) 3.01$ (rs2226: 56435992) \\
\hline
\end{tabular}

Table 3: Standardized [iHS] scores at the MC4R loci.

In the YRI population, we found that the core haplotype with a BMI risk allele (rs65670 G) and a BMI non-risk allele (rs571312 C) exhibited selection (REHH percentile: 99.9) (Table 2).

\section{iHS test}

Extreme positive scores ([iHS] > 2.5) indicate recent positive selection at a locus [20]. We observed that the highest [iHS] score of the SNP rs12326252 was 2.89 in the YRI population (Table 3), and the highest [iHS] score of the SNP rs2226 was 3.01 in East Asian populations (Table 3). These SNPs (rs12326252 and rs2226) were located at a region approximately a few hundred kilobases upstream of MC4R (Table 3). These SNPs were not linked with obesity, type 2 diabetes, or insulin resistance but may be linked with unknown phenotypes associated with MC4R.

\section{Discussion}

Charles Darwin originally defined natural selection in On the Origin of Species, published in 1859 [30]. Various adaptations to changes in food supply, lifestyle, and geography may have initiated the selection of genes associated with metabolism of glucose $[7,8]$, lipids, carbohydrates, and energy. During the past 10,000 years of human history, some important genes may have been the target of selection, becoming more differentiated to allow human populations to adapt and survive in different environments with different geography and different food supply [8]. The selected genes, therefore, could be historical footprints to our modern genome.

Evaluating gene selection can be both complex and difficult, but efforts to discover selection in genes associated with obesity, type 2 diabetes, and insulin resistance could be extremely useful in clinical medicine for the treatment of obesity and diabetes based on the genotypes of selected obesity and diabetes genes. The prevalence of obesity and diabetes is increasing steadily, and both conditions can lead to the development of serious complications. However, differences in the prevalence of obesity among ethnic groups may be not only because of genetic factors, but also because of environmental factors.

According to the 2008 WHO Report, worldwide prevalence of obesity has increased greatly in the past 3 decades and has more than doubled since 1980 . Furthermore, obesity is reported to be a highly heritable disease [1,2]. According to the 2007-2008 US National Health and Nutrition Examination Survey (NHANES), the prevalence of obesity among US adults showed that $32.8 \%$ of non-Hispanic whites, $44.1 \%$ of non-Hispanic blacks, and $39.3 \%$ of Mexican Americans were obese [3]. These findings demonstrated that there was a difference in the prevalence of obesity between racial and ethnic groups.
In particular, $M C 4 R$ is one of the major obesity genes [11$14,16,31,32]$, and is associated with energy expenditure, food intake, and BMI [9]. MC4R is a seven transmembrane G-protein coupled receptor and is highly expressed in the hypothalamus $[9,10]$. MC4Rdeficient mice showed a maturity onset obesity syndrome associated with hyperphagia, hyperinsulinemia, and hyperglycemia [32]. The melanocortin signaling plays important roles in the control of appetite and weight. Frameshift mutations in the MC4R gene were found to be associated with a dominant form of obesity [16,31]. Common variations near $M C 4 R$ were found to be associated with obesity, type 2 diabetes, and insulin resistance [11-15].

In this study, we detected the highest Fst values in one BMIassociated SNP (rs7227255; Fst $=0.42$ ) and one type 2 diabetesassociated SNP (rs11873305; Fst=0.41) (Table 1), and demonstrated high population differentiation and natural selection at the MC4R gene loci in HapMap populations. The two SNPs (rs7227255 and rs11873305) were located in a region approximately 9-16 kb upstream of MC4R. We suggest that the rs7227255 C risk allele may be a thrifty genotype [28]. In a phylogenetic analysis, $M C 4 R$ was reported to be subject to strong purifying selection [33].

In conclusion, these findings are very meaningful for clinical medicine and the first report that two SNPs associated with type 2 diabetes and obesity exhibited high Fst values and natural selection at the MC4R one-gene loci. We propose that the adaptive evolution of the genes associated with obesity, type 2 diabetes, and insulin resistance, especially genes involved in the MC4R pathway, such as leptin, leptin receptor, agouti-related protein (AGRP), and pro-opiomelanocortin (POMC), needs to be investigated further. Furthermore, we suggest that multiple genetic polymorphisms at the MC4R gene loci may lead to differences in resistance to obesity among ethnic groups, based on their current food supply and lifestyles.

\section{Acknowledgement}

We want to thank Kyoko Yoshiuchi for secretarial assistance.

The protocol for this research project has been approved by an Ethics Committee of Yoshiuchi Medical Diabetes Institute within which the work was undertaken and that it conforms to the provisions of the Declaration of Helsinki in 1995 (as revised in Edinburgh 2000)

\section{References}

1. Stunkard AJ, Foch TT, Hrubec Z (1986) A twin study of human obesity. JAMA 256: 51-54.

2. Maes HH, Neale MC, Eaves LJ (1997) Genetic and environmental factors in relative body weight and human adiposity. Behav Genet 27: 325-351. 
Citation: Yoshiuchi I (2013) Two SNPs Associated with Type 2 Diabetes and Obesity at Melanocortin-4 Receptor Gene Loci Exhibited High Fst Values and Natural Selection. J Diabetes Metab S11: 005. doi:10.4172/2155-6156.S11-005

Page 4 of 4

3. Flegal KM, Carroll MD, Ogden CL, Curtin LR (2010) Prevalence and trends in obesity among US adults, 1999-2008. JAMA 303: 235-241.

4. Diamond $J$ (2002) Evolution, consequences and future of plant and animal domestication. Nature 418: 700-707

5. Tishkoff SA, Varkonyi R, Cahinhinan N, Abbes S, Argyropoulos G, et al. (2001) Haplotype diversity and linkage disequilibrium at human G6PD: recent origin of alleles that confer malarial resistance. Science 293: 455-462.

6. Sabeti PC, Reich DE, Higgins JM, Levine HZ, Richter DJ, et al. (2002) Detecting recent positive selection in the human genome from haplotype structure. Nature 419: 832-837.

7. Helgason A, Pálsson S, Thorleifsson G, Grant SF, Emilsson V, et al. (2007) Refining the impact of TCF7L2 gene variants on type 2 diabetes and adaptive evolution. Nat Genet 39: 218-225.

8. Yoshiuchi I (2012) Evidence of selection at insulin receptor substrate-1 gene loci. Acta Diabetol.

9. Xu B, Goulding EH, Zang K, Cepoi D, Cone RD, et al. (2003) Brain-derived neurotrophic factor regulates energy balance downstream of melanocortin-4 receptor. Nat Neurosci 6: 736-742.

10. Gantz I, Miwa H, Konda Y, Shimoto Y, Tashiro T, et al. (1993) Molecula cloning, expression, and gene localization of a fourth melanocortin receptor. J Biol Chem 268: 15174-15179.

11. Loos RJ, Lindgren CM, Li S, Wheeler E, Zhao JH, et al. (2008) Common variants near MC4R are associated with fat mass, weight and risk of obesity. Nat Genet 40: 768-775.

12. Chambers JC, Elliott $P$, Zabaneh D, Zhang W, Li Y, et al. (2008) Common genetic variation near MC4R is associated with waist circumference and insulin resistance. Nat Genet 40: 716-718.

13. Speliotes EK, Willer CJ, Berndt SI, Monda KL, Thorleifsson G, et al. (2010) Association analyses of 249,796 individuals reveal 18 new loci associated with body mass index. Nat Genet 42: 937-948.

14. Willer CJ, Speliotes EK, Loos RJ, Li S, Lindgren CM, et al. (2009) Six new loci associated with body mass index highlight a neuronal influence on body weight regulation. Nat Genet 41: 25-34

15. Morris AP, Voight BF, Teslovich TM, Ferreira T, Segrè AV, et al. (2012) Largescale association analysis provides insights into the genetic architecture and pathophysiology of type 2 diabetes. Nat Genet 44: 981-990.

16. Farooqi IS, Keogh JM, Yeo GS, Lank EJ, Cheetham T, et al. (2003) Clinica spectrum of obesity and mutations in the melanocortin 4 receptor gene. $\mathrm{N}$ Engl J Med 348: 1085-1095.

17. International Hap Map Consortium (2005) A haplotype map of the human genome. Nature 437: 1299-1320.
18. Novembre J, Di Rienzo A (2009) Spatial patterns of variation due to natural selection in humans. Nat Rev Genet 10: 745-755.

19. Holsinger KE, Weir BS (2009) Genetics in geographically structured populations: defining, estimating and interpreting $\mathrm{F}(\mathrm{ST})$. Nat Rev Genet 10 : 639-650.

20. Voight BF, Kudaravalli S, Wen X, Pritchard JK (2006) A map of recent positive selection in the human genome. PLoS Biol 4: e72.

21. Excoffier L, Laval G, Schneider S (2007) Arlequin (version 3.0): an integrated software package for population genetics data analysis. Evol Bioinform Online 1: $47-50$.

22. Southam L, Soranzo N, Montgomery SB, Frayling TM, McCarthy MI, et al. (2009) Is the thrifty genotype hypothesis supported by evidence based on confirmed type 2 diabetes- and obesity-susceptibility variants? Diabetologia 52: $1846-1851$.

23. Mountain JL, Risch N (2004) Assessing genetic contributions to phenotypic differences among 'racial' and 'ethnic' groups. Nat Genet 36: S48-53.

24. Bersaglieri T, Sabeti PC, Patterson N, Vanderploeg T, Schaffner SF, et al (2004) Genetic signatures of strong recent positive selection at the lactase gene. Am J Hum Genet 74: 1111-1120.

25. Wooding S, Kim UK, Bamshad MJ, Larsen J, Jorde LB, et al. (2004) Natura selection and molecular evolution in PTC, a bitter-taste receptor gene. Am J Hum Genet 74: 637-646.

26. Bamshad MJ, Mummidi S, Gonzalez E, Ahuja SS, Dunn DM, et al. (2002) A strong signature of balancing selection in the 5' cis-regulatory region of CCR5. Proc Natl Acad Sci U S A 99: 10539-10544.

27. Pickrell JK, Coop G, Novembre J, Kudaravalli S, Li JZ, et al. (2009) Signals of recent positive selection in a worldwide sample of human populations. Genome Res 19: 826-837.

28. Neel JV (1962) Diabetes mellitus: a "thrifty" genotype rendered detrimental by "progress"? Am J Hum Genet 14: 353-362.

29. Kleinjan DA, van Heyningen V (2005) Long-range control of gene expression: emerging mechanisms and disruption in disease. Am J Hum Genet 76: 8-32.

30. Darwin C (1859) The Origin of Species by Means of Natural Selection. Murray London.

31. Vaisse C, Clement K, Guy-Grand B, Froguel P (1998) A frameshift mutation in human MC4R is associated with a dominant form of obesity. Nat Genet 20 : 113-114.

32. Huszar D, Lynch CA, Fairchild-Huntress V, Dunmore JH, Fang Q, et al. (1997) Targeted disruption of the melanocortin-4 receptor results in obesity in mice. Cell 88: 131-141.

33. Hughes DA, Hinney A, Brumm H, Wermter AK, Biebermann $\mathrm{H}$, et al. (2009) Increased constraints on MC4R during primate and human evolution. Hum Genet 124: 633-647. 